\title{
Iterative Approximation of Common Fixed Points of Two Nonself Asymptotically Nonexpansive Mappings
}

\author{
Esref Turkmen, ${ }^{1}$ Safeer Hussain Khan, ${ }^{2}$ and Murat Ozdemir ${ }^{1}$ \\ ${ }^{1}$ Department of Mathematics, Faculty of Science, Ataturk University, 25240 Erzurum, Turkey \\ ${ }^{2}$ Department of Mathematics, Statistics and Physics, Qatar University, Doha 2713, Qatar
}

Correspondence should be addressed to Murat Ozdemir, mozdemir@atauni.edu.tr

Received 11 October 2010; Accepted 17 February 2011

Academic Editor: Xiaohui Liu

Copyright (C) 2011 Esref Turkmen et al. This is an open access article distributed under the Creative Commons Attribution License, which permits unrestricted use, distribution, and reproduction in any medium, provided the original work is properly cited.

Suppose that $K$ is nonempty closed convex subset of a uniformly convex and smooth Banach space $E$ with $P$ as a sunny nonexpansive retraction and $F:=F\left(T_{1}\right) \cap F\left(T_{2}\right)=\left\{x \in K: T_{1} x=\right.$ $\left.T_{2} x=x\right\} \neq \emptyset$. Let $T_{1}, T_{2}: K \rightarrow E$ be two weakly inward nonself asymptotically nonexpansive mappings with respect to $P$ with two sequences $\left\{k_{n}^{(i)}\right\} \subset[1, \infty)$ satisfying $\sum_{n=1}^{\infty}\left(k_{n}^{(i)}-1\right)<\infty(i=$ $1,2)$, respectively. For any given $x_{1} \in K$, suppose that $\left\{x_{n}\right\}$ is a sequence generated iteratively by $x_{n+1}=\left(1-\alpha_{n}\right)\left(P T_{1}\right)^{n} y_{n}+\alpha_{n}\left(P T_{2}\right)^{n} y_{n}, y_{n}=\left(1-\beta_{n}\right) x_{n}+\beta_{n}\left(P T_{1}\right)^{n} x_{n}, n \in \mathbb{N}$, where $\left\{\alpha_{n}\right\}$ and $\left\{\beta_{n}\right\}$ are sequences in $[a, 1-a]$ for some $a \in(0,1)$. Under some suitable conditions, the strong and weak convergence theorems of $\left\{x_{n}\right\}$ to a common fixed point of $T_{1}$ and $T_{2}$ are obtained.

\section{Introduction}

Let $E$ be a real Banach space with $K$, its nonempty subset. Let $T: K \rightarrow K$ be a mapping. A point $x \in K$ is called a fixed point of $T$ if and only if $T x=x$. In this paper, $\mathbb{N}$ stands for the set of natural numbers. We will also denote by $F(T)$ the set of fixed points of $T$, that is, $F(T)=\{x \in K: T x=x\}$ and by $F:=F\left(T_{1}\right) \cap F\left(T_{2}\right)$, the set of common fixed points of two mappings $T_{1}$ and $T_{2} . T$ is called asymptotically nonexpansive if for a sequence $\left\{k_{n}\right\} \subset[1, \infty)$ with $\lim _{n \rightarrow \infty} k_{n}=1,\left\|T^{n} x-T^{n} y\right\| \leq k_{n}\|x-y\|$ for all $x, y \in K$ and all $n \in \mathbb{N}$. $T$ is called uniformly $L$-Lipschitzian if for some $L>0,\left\|T^{n} x-T^{n} y\right\| \leq L\|x-y\|$ for all $n \in \mathbb{N}$ and all $x, y \in K$. T is said to be nonexpansive if $\|T x-T y\| \leq\|x-y\|$ for all $x, y \in K$. Let $P: E \rightarrow K$ be a nonexpansive retraction of $E$ into $K$. A nonself-mapping $T: K \rightarrow E$ is called asymptotically nonexpansive (according to Chidume et al. [1]) if for a sequence $\left\{k_{n}\right\} \subset[1, \infty)$ with $\lim _{n \rightarrow \infty} k_{n}=1$, we have $\left\|T(P T)^{n-1} x-T(P T)^{n-1} y\right\| \leq k_{n}\|x-y\|$ for all $x, y \in K$ and $n \in \mathbb{N}$. $T$ is called uniformly 
$L$-Lipschitzian if for some $L>0,\left\|T(P T)^{n-1} x-T(P T)^{n-1} y\right\| \leq L\|x-y\|$ for all $n \in \mathbb{N}$ and all $x, y \in K$.

In what follows, we fix $x_{1} \in K$ as a starting point of the process under consideration, and take $\left\{\alpha_{n}\right\},\left\{\beta_{n}\right\}$ sequences in $(0,1)$.

Agarwal et al. [2] recently introduced the iteration process

$$
\begin{gathered}
x_{n+1}=\left(1-\alpha_{n}\right) T^{n} x_{n}+\alpha_{n} T^{n} y_{n}, \\
y_{n}=\left(1-\beta_{n}\right) x_{n}+\beta_{n} T^{n} x_{n}, \quad n \in \mathbb{N} .
\end{gathered}
$$

They showed that their process is independent of Mann and Ishikawa and converges faster than both of these. See Proposition 3.1 [2].

Obviously the above process deals with one self-mapping only. The case of two mappings in iteration processes has also remained under study since Das and Debata [3] gave and studied a two mappings scheme. Also see, for example, Takahashi and Tamura [4] and Khan and Takahashi [5]. Note that two mappings case, that is, approximating the common fixed points, has its own importance as it has a direct link with the minimization problem, see, for example, Takahashi [6].

Being an important generalization of the class of nonexpansive self-mappings, the class of asymptotically nonexpansive self-mappings was introduced by Goebel and Kirk [7] whereas the concept of asymptotically nonexpansive nonself-mappings was introduced by Chidume et al. [1] in 2003 as a generalization of asymptotically nonexpansive self-mappings. Actually they studied the iteration process

$$
x_{n+1}=P\left(\left(1-\alpha_{n}\right) x_{n}+\alpha_{n} T(P T)^{n-1} x_{n}\right), \quad n \in \mathbb{N} .
$$

Nonself asymptotically nonexpansive mappings have been studied by many authors [8-11]. Wang [10] studied the process

$$
\begin{gathered}
x_{n+1}=P\left(\left(1-\alpha_{n}\right) x_{n}+\alpha_{n} T_{1}\left(P T_{1}\right)^{n-1} y_{n}\right), \\
y_{n}=P\left(\left(1-\beta_{n}\right) x_{n}+\beta_{n} T_{2}\left(P T_{2}\right)^{n-1} x_{n}\right), \quad n \in \mathbb{N} .
\end{gathered}
$$

Very recently, Thianwan [12] considered a new iterative scheme (called projection type Ishikawa iteration) as follows:

$$
\begin{gathered}
x_{n+1}=P\left(\left(1-\alpha_{n}\right) y_{n}+\alpha_{n} T_{1}\left(P T_{1}\right)^{n-1} y_{n}\right), \\
y_{n}=P\left(\left(1-\beta_{n}\right) x_{n}+\beta_{n} T_{2}\left(P T_{2}\right)^{n-1} x_{n}\right), \quad n \in \mathbb{N} .
\end{gathered}
$$

As a matter of fact, if $T$ is a self-mapping, then $P$ is an identity mapping. In addition, if $T: K \rightarrow E$ is asymptotically nonexpansive and $P: E \rightarrow K$ is a nonexpansive retraction, then 
$P T: K \rightarrow K$ is asymptotically nonexpansive. Indeed, for all $x, y \in K$ and $n \in \mathbb{N}$, it follows that

$$
\begin{aligned}
\left\|(P T)^{n} x-(P T)^{n} y\right\| & =\left\|P T(P T)^{n-1} x-P T(P T)^{n-1} y\right\| \\
& \leq\left\|T(P T)^{n-1} x-T(P T)^{n-1} y\right\| \\
& \leq k_{n}\|x-y\| .
\end{aligned}
$$

The converse, however, may not be true. Therefore, Zhou et al. [13] introduced the following generalized definition recently.

Definition 1.1 (see [13]). Let $K$ be a nonempty subset of real normed linear space $E$. Let $P$ : $E \rightarrow K$ be the nonexpansive retraction of $E$ into $K$.

(i) A nonself-mapping $T: \mathrm{K} \rightarrow E$ is called asymptotically nonexpansive with respect to $P$ if there exists sequences $\left\{k_{n}\right\} \in[1, \infty)$ with $k_{n} \rightarrow 1$ as $n \rightarrow \infty$ such that

$$
\left\|(P T)^{n} x-(P T)^{n} y\right\| \leq k_{n}\|x-y\|, \quad \forall x, y \in K, n \in \mathbb{N} .
$$

(ii) A nonself-mapping $T: K \rightarrow E$ is said to be uniformly $L$-Lipschitzian with respect to $P$ if there exists a constant $L \geq 0$ such that

$$
\left\|(P T)^{n} x-(P T)^{n} y\right\| \leq L\|x-y\|, \quad \forall x, y \in K, n \in \mathbb{N} .
$$

Futhermore, by studying the following iterative process

$$
x_{1} \in K, \quad x_{n+1}=\alpha_{n} x_{n}+\beta_{n}\left(P T_{1}\right)^{n} x_{n}+\gamma_{n}\left(P T_{2}\right)^{n} x_{n}, \quad n \in \mathbb{N},
$$

where $\left\{\alpha_{n}\right\},\left\{\beta_{n}\right\}$, and $\left\{\gamma_{n}\right\}$ are three sequences in $[a, 1-a]$ for some $a \in(0,1)$, satisfying $\alpha_{n}+\beta_{n}+\gamma_{n}=1$, Zhou et al. [13] obtained some strong and weak convergence theorems for common fixed points of nonself asymptotically nonexpansive mappings with respect to $P$ in uniformly convex Banach spaces. As a consequence, the main results of Chidume et al. [1] were deduced.

Incorporating the ideas of Agarwal et al. [2], Thianwan [12], and Zhou et al. [13], a new two-step iterative scheme for two nonself asymptotically nonexpansive mappings is introduced and studied in this paper. Our process reads as follows.

Let $K$ be a nonempty closed convex subset of a real normed linear space $E$ with retraction $P$. Let $T_{1}, T_{2}: K \rightarrow E$ be two nonself asymptotically nonexpansive mappings with respect to $P$ :

$$
\begin{gathered}
x_{1} \in K, \\
x_{n+1}=\left(1-\alpha_{n}\right)\left(P T_{1}\right)^{n} y_{n}+\alpha_{n}\left(P T_{2}\right)^{n} y_{n}, \\
y_{n}=\left(1-\beta_{n}\right) x_{n}+\beta_{n}\left(P T_{1}\right)^{n} x_{n}, \quad n \in \mathbb{N},
\end{gathered}
$$


where $\left\{\alpha_{n}\right\}$ and $\left\{\beta_{n}\right\}$ are sequences in [0,1]. Following the method of Agarwal et al. [2], it is not difficult to see that our process is able to compute common fixed points at a rate better than (1.3) and (1.4).

Under suitable conditions, the sequence $\left\{x_{n}\right\}$ defined by (1.9) can also be generalized to iterative sequence with errors. Thus all the results proved in this paper can also be proved for the iterative process with errors. In this case our main iterative process (1.9) looks like

$$
\begin{gathered}
x_{1} \in K, \\
x_{n+1}=\alpha_{n}\left(P T_{1}\right)^{n} y_{n}+\beta_{n}\left(P T_{2}\right)^{n} y_{n}+\gamma_{n} u_{n}, \\
y_{n}=\alpha_{n}^{\prime} x_{n}+\beta_{n}^{\prime}\left(P T_{1}\right)^{n} x_{n}+\gamma_{n}^{\prime} v_{n}, \quad n \in \mathbb{N},
\end{gathered}
$$

where $\left\{\alpha_{n}\right\},\left\{\beta_{n}\right\},\left\{\gamma_{n}\right\},\left\{\alpha_{n}^{\prime}\right\},\left\{\beta_{n}^{\prime}\right\},\left\{\gamma_{n}^{\prime}\right\}$ are real sequences in $[0,1]$ satisfying $\alpha_{n}+\beta_{n}+\gamma_{n}=1=$ $\alpha_{n}^{\prime}+\beta_{n}^{\prime}+\gamma_{n}^{\prime}$ and $\left\{u_{n}\right\},\left\{v_{n}\right\}$ are bounded sequences in $K$. Observe that the iterative process (1.10) with errors reduces to the iterative process (1.9) when $\gamma_{n}=\gamma_{n}^{\prime}=0$.

\section{Preliminaries}

For the sake of convenience, we restate the following concepts and results.

Let $E$ be a Banach space with its dimension greater than or equal to 2 . The modulus of $E$ is the function $\delta_{E}(\varepsilon):(0,2] \rightarrow[0,1]$ defined by

$$
\delta_{E}(\varepsilon)=\inf \left\{1-\left\|\frac{1}{2}(x+y)\right\|:\|x\|=1,\|y\|=1, \varepsilon=\|x-y\|\right\} .
$$

A Banach space $E$ is uniformly convex if and only if $\delta_{E}(\varepsilon)>0$ for all $\varepsilon \in(0,2]$.

if

Let $E$ be a Banach space and $S(E)=\{x \in E:\|x\|=1\}$. The space $E$ is said to be smooth

$$
\lim _{t \rightarrow 0} \frac{\|x+t y\|-\|x\|}{t}
$$

exists for all $x, y \in S(E)$.

A subset $K$ of $E$ is said to be a retract if there exists a continuous mapping $P: E \rightarrow K$ such that $P x=x$ for all $x \in K$. A mapping $P: E \rightarrow E$ is said to be a retraction if $P^{2}=P$. Let $C$ and $K$ be subsets of a Banach space $E$. A mapping $P$ from $C$ into $K$ is called sunny if $P(P x+t(x-P x))=P x$ for $x \in C$ with $P x+t(x-P x) \in C$ and $t \geq 0$.

Note that, if $P$ is a retraction, then $P z=z$ for every $z \in R(P)$ (the range of $P$ ). It is well-known that every closed convex subset of a uniformly convex Banach space is a retract.

For any $x \in K$, the inward set $I_{K}(x)$ is defined as follows:

$$
I_{K}(x)=\{y \in E: y=x+\lambda(z-x), z \in K, \lambda \geq 0\} .
$$

A mapping $T: K \rightarrow E$ is said to satisfy the inward condition if $T x \in I_{K}(x)$ for all $x \in K . T$ is said to be weakly inward if $T x \in \mathrm{cl} I_{K}(x)$ for each $x \in K$, where $\mathrm{cl} I_{K}(x)$ is the closure of $I_{K}(x)$. 
A Banach space $E$ is said to satisfy Opial's condition if, for any sequence $\left\{x_{n}\right\}$ in $E$, $x_{n} \rightarrow x$ implies that

$$
\limsup _{n \rightarrow \infty}\left\|x_{n}-x\right\|<\limsup _{n \rightarrow \infty}\left\|x_{n}-y\right\|
$$

for all $y \in E$ with $y \neq x$, where $x_{n} \rightarrow x$ means that $\left\{x_{n}\right\}$ converges weakly to $x$.

Recall that the mapping $T: K \rightarrow K$ with $F(T) \neq \emptyset$ is said to satisfy condition $(A)[14]$ if there is a nondecreasing function $f:[0, \infty) \rightarrow[0, \infty)$ with $f(0)=0, f(t)>0$ for all $t \in(0, \infty)$ such that $\|x-T x\| \geq f(d(x, F(T)))$ for all $x \in K$, where $d(x, F(T))=\inf \{\|x-p\|: p \in F(T)\}$. Khan and Fukhar-ud-din [15] modified condition $(A)$ for two mappings as follows: Two mappings $T_{1}, T_{2}: K \rightarrow K$ are said to satisfy condition $\left(A^{\prime}\right)$ [15] if there is a nondecreasing function $f:[0, \infty) \rightarrow[0, \infty)$ with $f(0)=0, f(t)>0$ for all $t \in(0, \infty)$ such that

$$
\frac{1}{2}\left(\left\|x-T_{1} x\right\|+\left\|x-T_{2} x\right\|\right) \geq f(d(x, F))
$$

for all $x \in K$, where $d(x, F)=\inf \left\{\|x-p\|: p \in F:=F\left(T_{1}\right) \cap F\left(T_{2}\right)\right\}$.

Note that condition $\left(A^{\prime}\right)$ reduces to condition $(A)$ when $T_{1}=T_{2}$. It is also well-known that condition $(A)$ is weaker than demicompactness or semicompactness, see [14].

A mapping $T$ with domain $D(T)$ and range $R(T)$ in $E$ is said to be demiclosed at $p$ if whenever $\left\{x_{n}\right\}$ is a sequence in $D(T)$ such that $\left\{x_{n}\right\}$ converges weakly to $x^{*} \in D(T)$ and $\left\{T x_{n}\right\}$ converges strongly to $p$, then $T x^{*}=p$.

We need the following lemmas for our main results.

Lemma 2.1 (see [16]). If $\left\{r_{n}\right\},\left\{t_{n}\right\}$ are two sequences of nonnegative real numbers such that

$$
r_{n+1} \leq\left(1+t_{n}\right) r_{n}, \quad n \in \mathbb{N}
$$

and $\sum_{n=1}^{\infty} t_{n}<\infty$, then $\lim _{n \rightarrow \infty} r_{n}$ exists.

Lemma 2.2 (see [17]). Suppose that $E$ is a uniformly convex Banach space and $0<p \leq t_{n} \leq q<1$ for all $n \in \mathbb{N}$. Also, suppose that $\left\{x_{n}\right\}$ and $\left\{y_{n}\right\}$ are sequences of $E$ such that

$$
\limsup _{n \rightarrow \infty}\left\|x_{n}\right\| \leq r, \quad \limsup _{n \rightarrow \infty}\left\|y_{n}\right\| \leq r, \quad \lim _{n \rightarrow \infty}\left\|\left(1-t_{n}\right) x_{n}+t_{n} y_{n}\right\|=r
$$

hold for some $r \geq 0$. Then $\lim _{n \rightarrow \infty}\left\|x_{n}-y_{n}\right\|=0$.

Lemma 2.3 (see [18]). Let $E$ be real smooth Banach space, let $K$ be nonempty closed convex subset of $E$ with $P$ as a sunny nonexpansive retraction, and let $T: K \rightarrow E$ be a mapping satisfying weakly inward condition. Then $F(P T)=F(T)$.

Lemma 2.4 (see [1]). Let E be a uniformly convex Banach space and let $C$ be a nonempty closed convex subset of $E$. Let $T$ be a nonself asymptotically nonexpansive mapping. Then $I-T$ is demiclosed with respect to zero, that is, $x_{n} \rightarrow x$ and $x_{n}-T x_{n} \rightarrow 0$ imply that $T x=x$. 


\section{Main Results}

\subsection{Convergence Theorems in Real Banach Spaces}

In this section, we prove the strong convergence of the iteration scheme (1.9) to a common fixed point of nonself asymptotically nonexpansive mappings $T_{1}$ and $T_{2}$ with respect to $P$ in real Banach spaces. Let $T_{1}, T_{2}: K \rightarrow E$ be two nonself asymptotically nonexpansive mappings with respect to $P$ with sequences $\left\{k_{n}^{(i)}\right\} \subset[1, \infty)$ satisfying $\sum_{n=1}^{\infty}\left(k_{n}^{(i)}-1\right)<\infty(i=$ $1,2)$, respectively. Put $k_{n}=\max \left\{k_{n}^{(1)}, k_{n}^{(2)}\right\}$, then obviously $\sum_{n=1}^{\infty}\left(k_{n}-1\right)<\infty$. From now on we will take this sequence $\left\{k_{n}\right\}$ for both $T_{1}$ and $T_{2}$.

We first prove the following lemmas.

Lemma 3.1. Let $E$ be a real normed linear space and $K$ a nonempty closed convex subset of $E$ which is also a nonexpansive retract of $E$. Let $T_{1}, T_{2}: K \rightarrow E$ be two nonself asymptotically nonexpansive mappings with respect to $P$ with sequence $\left\{k_{n}\right\} \subset[1, \infty)$ satisfying $\sum_{n=1}^{\infty}\left(k_{n}-1\right)<\infty$. Suppose that $\left\{x_{n}\right\}$ is defined by (1.9) and $F \neq \emptyset$. Then,

(i) $\lim _{n \rightarrow \infty}\left\|x_{n}-p\right\|$ exists for all $p \in F$;

(ii) there exists a constant $M>0$ such that $\left\|x_{n+m}-p\right\| \leq M\left\|x_{n}-p\right\|$ for all $m, n \in \mathbb{N}$ and $p \in F$.

Proof. (i) Let $p \in F$. From (1.9), we have

$$
\begin{aligned}
\left\|y_{n}-p\right\| & =\left\|\left(1-\beta_{n}\right) x_{n}+\beta_{n}\left(P T_{1}\right)^{n} x_{n}-p\right\| \\
& \leq\left(1-\beta_{n}\right)\left\|x_{n}-p\right\|+\beta_{n}\left\|\left(P T_{1}\right)^{n} x_{n}-p\right\| \\
& \leq\left(1-\beta_{n}\right)\left\|x_{n}-p\right\|+\beta_{n} k_{n}\left\|x_{n}-p\right\| \\
& =\left(1+\beta_{n}\left(k_{n}-1\right)\right)\left\|x_{n}-p\right\| \\
& \leq\left(1+\left(k_{n}-1\right)\right)\left\|x_{n}-p\right\| \\
& =k_{n}\left\|x_{n}-p\right\| .
\end{aligned}
$$

By (3.1) and (1.9), we obtain

$$
\begin{aligned}
\left\|x_{n+1}-p\right\| & =\left\|\left(1-\alpha_{n}\right)\left(P T_{1}\right)^{n} y_{n}-\alpha_{n}\left(P T_{2}\right)^{n} y_{n}-p\right\| \\
& =\left\|\left(1-\alpha_{n}\right)\left(\left(P T_{1}\right)^{n} y_{n}-p\right)-\alpha_{n}\left(\left(P T_{2}\right)^{n} y_{n}-p\right)\right\| \\
& \leq\left(1-\alpha_{n}\right) k_{n}\left\|y_{n}-p\right\|+\alpha_{n} k_{n}\left\|y_{n}-p\right\| \\
& =k_{n}\left\|y_{n}-p\right\| \\
& \leq k_{n}^{2}\left\|x_{n}-p\right\| \\
& =\left(1+\left(k_{n}^{2}-1\right)\right)\left\|x_{n}-p\right\| .
\end{aligned}
$$

Note that $\sum_{n=1}^{\infty}\left(k_{n}-1\right)<\infty$ is equivalent to $\sum_{n=1}^{\infty}\left(k_{n}^{2}-1\right)<\infty$. Thus, by (3.2) and Lemma 2.1, $\lim _{n \rightarrow \infty}\left\|x_{n}-p\right\|$ exists for all $p \in F(T)$. 
(ii) From (3.2), we have

$$
\left\|x_{n+1}-p\right\| \leq k_{n}^{2}\left\|x_{n}-p\right\|
$$

It is well known that $1+x \leq e^{x}$ for all $x \geq 0$. Using it for the above inequality, we have

$$
\begin{aligned}
\left\|x_{n+m}-p\right\| & \leq\left(1+\left(k_{n+m-1}^{2}-1\right)\right)\left\|x_{n+m-1}-p\right\| \\
& \leq e^{k_{n+m-1}^{2}-1}\left\|x_{n+m-1}-p\right\| \\
& \leq e^{k_{n+m-1}^{2}-1}\left[\left(1+\left(k_{n+m-2}^{2}-1\right)\right)\left\|x_{n+m-2}-p\right\|\right] \\
& \leq e^{k_{n+m-1}^{2}-1+k_{n+m-2}^{2}-1}\left\|x_{n+m-2}-p\right\| \\
& \vdots \\
& \leq e^{\sum_{j=n}^{n+m-1}\left(k_{j}^{2}-1\right)}\left\|x_{n}-p\right\| \\
& \leq M\left\|x_{n}-p\right\|,
\end{aligned}
$$

where $M=e^{\sum_{j=n}^{n+m-1}\left(k_{j}^{2}-1\right)}$. That is, $\left\|x_{n+m}-p\right\| \leq M\left\|x_{n}-p\right\|$ for all $m, n \in \mathbb{N}$ and $p \in F$.

Theorem 3.2. Let $E$ be a real Banach space and $K$ a nonempty closed convex subset of $E$ which is also a nonexpansive retract of $E$. Let $T_{1}, T_{2}: K \rightarrow E$ be two nonself asymptotically nonexpansive mappings with respect to $P$ with sequence $\left\{k_{n}\right\} \subset[1, \infty)$ satisfying $\sum_{n=1}^{\infty}\left(k_{n}-1\right)<\infty$. Suppose that $\left\{x_{n}\right\}$ is defined by (1.9) and $F \neq \emptyset$. Then, $\left\{x_{n}\right\}$ converges strongly to a common fixed point of $T_{1}$ and $T_{2}$ if and only if $\liminf _{n \rightarrow \infty} d\left(x_{n}, F\right)=0$, where $d\left(x_{n}, F\right)=\inf \{\|x-p\|: p \in F\}$.

Proof. The necessity of the conditions is obvious. Thus, we need only prove the sufficiency. Suppose that $\liminf _{n \rightarrow \infty} d\left(x_{n}, F\right)=0$. From (3.2), we have

$$
d\left(x_{n+1}, F\right) \leq\left(1+\left(k_{n}^{2}-1\right)\right) d\left(x_{n}, F\right) .
$$

As $\sum_{n=1}^{\infty}\left(k_{n}-1\right)<\infty$, therefore $\lim _{n \rightarrow \infty} d\left(x_{n}, F\right)$ exists by Lemma 2.1. But by hypothesis $\lim \inf _{n \rightarrow \infty} d\left(x_{n}, F\right)=0$, therefore we must have $\lim _{n \rightarrow \infty} d\left(x_{n}, F\right)=0$.

Next we show that $\left\{x_{n}\right\}$ is a Cauchy sequence. Let $\varepsilon>0$. Since $\lim _{n \rightarrow \infty} d\left(x_{n}, F\right)=0$, therefore there exists a constant $n_{0}$ such that for all $n \geq n_{0}$, we have

$$
d\left(x_{n}, F\right)<\frac{\varepsilon}{4 M}
$$

where $M>0$ is the constant in Lemma 3.1(ii). So we can find $p^{\prime} \in F$ such that

$$
\left\|x_{n_{0}}-p^{\prime}\right\|<\frac{\varepsilon}{2 M}
$$


Using Lemma 3.1(ii), we have for all $n \geq n_{0}$ and $m \in \mathbb{N}$ that

$$
\begin{aligned}
\left\|x_{n+m}-x_{n}\right\| & \leq\left\|x_{n+m}-p^{\prime}\right\|+\left\|x_{n}-p^{\prime}\right\| \\
& \leq M\left\|x_{n_{0}}-p^{\prime}\right\|+M\left\|x_{n_{0}}-p^{\prime}\right\| \\
& =2 M\left\|x_{n_{0}}-p^{\prime}\right\| \\
& <\varepsilon .
\end{aligned}
$$

Hence $\left\{x_{n}\right\}$ is a Cauchy sequence in a closed subset $K$ of a Banach space $E$, therefore it must converge to a point in $K$. Let $\lim _{n \rightarrow \infty} x_{n}=q$. Now, $\lim _{n \rightarrow \infty} d\left(x_{n}, F\right)=0$ gives that $d(q, F)=0$. Since the set of fixed points of asymptotically nonexpansive mappings is closed, we have $q \in F$. This completes the proof of the theorem.

On the lines similar to this theorem, we can also prove the following theorem which addresses the error terms.

Theorem 3.3. Let $E$ be a real Banach space and $K$ a nonempty closed convex subset of $E$ which is also a nonexpansive retract of $E$. Let $T_{1}, T_{2}: K \rightarrow E$ be two asymptotically nonexpansive mappings with respect to $P$ with sequence $\left\{k_{n}\right\} \subset[1, \infty)$ satisfying $\sum_{n=1}^{\infty}\left(k_{n}-1\right)<\infty$. Suppose that $\left\{x_{n}\right\}$ is defined by (1.10) with $\sum_{n=1}^{\infty} \gamma_{n}<\infty, \sum_{n=1}^{\infty} \gamma_{n}^{\prime}<\infty$ and $F \neq \emptyset$, Then, $\left\{x_{n}\right\}$ converges strongly to a common fixed point of $T_{1}$ and $T_{2}$ if and only if $\liminf _{n \rightarrow \infty} d\left(x_{n}, F\right)=0$, where $d\left(x_{n}, F\right)=\inf \{\|x-p\|: p \in F\}$.

\subsection{Convergence Theorems in Real Uniformly Convex Banach Spaces}

In this section, we prove the strong and weak convergence of the sequence defined by the iteration scheme (1.9) to a common fixed point of nonself asymptotically nonexpansive mappings $T_{1}$ and $T_{2}$ with respect to $P$ in real uniformly convex and smooth Banach space. We first prove the following lemma.

Lemma 3.4. Let $K$ be a nonempty closed convex subset of a real uniformly convex Banach space $E$. Let $T_{1}, T_{2}: K \rightarrow E$ be two nonself asymptotically nonexpansive mappings with respect to $P$ with sequence $\left\{k_{n}\right\} \subset[1, \infty)$ satisfying $\sum_{n=1}^{\infty}\left(k_{n}-1\right)<\infty$. Suppose that $\left\{x_{n}\right\}$ is defined by $(1.9)$, where $\left\{\alpha_{n}\right\}$ and $\left\{\beta_{n}\right\}$ are sequences in $[a, 1-a]$ for some $a \in(0,1)$. If $F \neq \emptyset$, then

$$
\lim _{n \rightarrow \infty}\left\|x_{n}-\left(P T_{1}\right) x_{n}\right\|=\lim _{n \rightarrow \infty}\left\|x_{n}-\left(P T_{2}\right) x_{n}\right\|=0
$$

Proof. By Lemma 3.1(i), $\lim _{n \rightarrow \infty}\left\|x_{n}-p\right\|$ exists. Assume that $\lim _{n \rightarrow \infty}\left\|x_{n}-p\right\|=c$. If $c=0$, the conclusion is obvious. Suppose $c>0$. Taking lim sup on both sides in that inequality (3.1), we have

$$
\underset{n \rightarrow \infty}{\limsup }\left\|y_{n}-p\right\| \leq \limsup _{n \rightarrow \infty}\left\|x_{n}-p\right\|=\lim _{n \rightarrow \infty}\left\|x_{n}-p\right\|=c .
$$


Thus $\left\|\left(P T_{1}\right)^{n} y_{n}-p\right\| \leq k_{n}\left\|y_{n}-p\right\|$ for all $n \in \mathbb{N}$ implies that

$$
\limsup _{n \rightarrow \infty}\left\|\left(P T_{1}\right)^{n} y_{n}-p\right\| \leq c
$$

Similarly,

$$
\limsup _{n \rightarrow \infty}\left\|\left(P T_{2}\right)^{n} y_{n}-p\right\| \leq c
$$

Further,

$$
\begin{aligned}
c & =\lim _{n \rightarrow \infty}\left\|x_{n+1}-p\right\| \\
& =\lim _{n \rightarrow \infty}\left\|\left(1-\alpha_{n}\right)\left(P T_{1}\right)^{n} y_{n}+\alpha_{n}\left(P T_{2}\right)^{n} y_{n}-p\right\| \\
& =\lim _{n \rightarrow \infty}\left\|\left(1-\alpha_{n}\right)\left(\left(P T_{1}\right)^{n} y_{n}-p\right)+\alpha_{n}\left(\left(P T_{2}\right)^{n} y_{n}-p\right)\right\| \\
& \leq \lim _{n \rightarrow \infty}\left[\left(1-\alpha_{n}\right)\left\|\limsup _{n \rightarrow \infty}\left(\left(P T_{1}\right)^{n} y_{n}-p\right)\right\|+\alpha_{n}\left\|\limsup _{n \rightarrow \infty}\left(\left(P T_{2}\right)^{n} y_{n}-p\right)\right\|\right] \\
& \leq \lim _{n \rightarrow \infty}\left[\left(1-\alpha_{n}\right) c+\alpha_{n} c\right] \\
& =c
\end{aligned}
$$

gives that

$$
\lim _{n \rightarrow \infty}\left\|\left(1-\alpha_{n}\right)\left(\left(P T_{1}\right)^{n} y_{n}-p\right)+\alpha_{n}\left(\left(P T_{2}\right)^{n} y_{n}-p\right)\right\|=c
$$

Hence, using (3.11), (3.12), (3.14), and Lemma 2.2, we obtain

$$
\lim _{n \rightarrow \infty}\left\|\left(P T_{2}\right)^{n} y_{n}-\left(P T_{1}\right)^{n} y_{n}\right\|=0
$$

Noting that

$$
\begin{aligned}
\left\|x_{n+1}-p\right\| & =\left\|\left(1-\alpha_{n}\right)\left(P T_{1}\right)^{n} y_{n}+\alpha_{n}\left(P T_{2}\right)^{n} y_{n}-p\right\| \\
& \leq\left\|\left(P T_{1}\right)^{n} y_{n}-p\right\|+\alpha_{n}\left\|\left(P T_{2}\right)^{n} y_{n}-\left(P T_{1}\right)^{n} y_{n}\right\| \\
& \leq k_{n}\left\|y_{n}-p\right\|+\alpha_{n}\left\|\left(P T_{2}\right)^{n} y_{n}-\left(P T_{1}\right)^{n} y_{n}\right\|
\end{aligned}
$$

which yields that

$$
c \leq \liminf _{n \rightarrow \infty}\left\|y_{n}-p\right\| .
$$


By (3.10) and (3.17), we obtain

$$
\lim _{n \rightarrow \infty}\left\|y_{n}-p\right\|=c
$$

Moreover, $\left\|\left(P T_{1}\right)^{n} x_{n}-p\right\| \leq k_{n}\left\|x_{n}-p\right\|$ for all $n \in \mathbb{N}$ implies that

$$
\limsup _{n \rightarrow \infty}\left\|\left(P T_{1}\right)^{n} x_{n}-p\right\| \leq c .
$$

Hence

$$
\begin{aligned}
c & =\lim _{n \rightarrow \infty}\left\|y_{n}-p\right\| \\
& =\lim _{n \rightarrow \infty}\left\|\left(1-\beta_{n}\right) x_{n}+\beta_{n}\left(P T_{1}\right)^{n} x_{n}-p\right\| \\
& =\lim _{n \rightarrow \infty}\left\|\left(1-\beta_{n}\right)\left(x_{n}-p\right)+\beta_{n}\left(\left(P T_{1}\right)^{n} x_{n}-p\right)\right\| \\
& \leq \lim _{n \rightarrow \infty}\left[\left(1-\beta_{n}\right)\left\|\limsup _{n \rightarrow \infty}\left(x_{n}-p\right)\right\|+\beta_{n}\left\|\limsup _{n \rightarrow \infty}\left(\left(P T_{1}\right)^{n} x_{n}-p\right)\right\|\right] \\
& \leq \lim _{n \rightarrow \infty}\left[\left(1-\beta_{n}\right) c+\beta_{n} c\right] \\
& =c
\end{aligned}
$$

gives that

$$
\lim _{n \rightarrow \infty}\left\|\left(1-\beta_{n}\right)\left(x_{n}-p\right)+\beta_{n}\left(\left(P T_{1}\right)^{n} x_{n}-p\right)\right\|=c .
$$

Again by Lemma 2.2, we obtain

$$
\lim _{n \rightarrow \infty}\left\|\left(P T_{1}\right)^{n} x_{n}-x_{n}\right\|=0
$$

In addition, from $y_{n}=\left(1-\beta_{n}\right) x_{n}+\beta_{n}\left(P T_{1}\right)^{n} x_{n}$, we have

$$
\left\|y_{n}-x_{n}\right\|=\beta_{n}\left\|\left(P T_{1}\right)^{n} x_{n}-x_{n}\right\| .
$$

Hence by (3.22),

$$
\lim _{n \rightarrow \infty}\left\|y_{n}-x_{n}\right\|=0
$$

Also

$$
\begin{aligned}
\left\|\left(P T_{2}\right)^{n} y_{n}-x_{n}\right\| & \leq\left\|\left(P T_{2}\right)^{n} y_{n}-\left(P T_{1}\right)^{n} y_{n}\right\|+\left\|\left(P T_{1}\right)^{n} y_{n}-\left(P T_{1}\right)^{n} x_{n}\right\|+\left\|\left(P T_{1}\right)^{n} x_{n}-x_{n}\right\| \\
& \leq\left\|\left(P T_{2}\right)^{n} y_{n}-\left(P T_{1}\right)^{n} y_{n}\right\|+k_{n}\left\|y_{n}-x_{n}\right\|+\left\|\left(P T_{1}\right)^{n} x_{n}-x_{n}\right\|
\end{aligned}
$$


implies by (3.15), (3.22), and (3.24) that

$$
\lim _{n \rightarrow \infty}\left\|\left(P T_{2}\right)^{n} y_{n}-x_{n}\right\|=0
$$

Using (3.24) and (3.26), we obtain

$$
\begin{aligned}
\left\|\left(P T_{2}\right)^{n} x_{n}-x_{n}\right\| & \leq\left\|\left(P T_{2}\right)^{n} x_{n}-\left(P T_{2}\right)^{n} y_{n}\right\|+\left\|\left(P T_{2}\right)^{n} y_{n}-x_{n}\right\| \\
& \leq k_{n}\left\|x_{n}-y_{n}\right\|+\left\|\left(P T_{2}\right)^{n} y_{n}-x_{n}\right\|,
\end{aligned}
$$

so that

$$
\lim _{n \rightarrow \infty}\left\|\left(P T_{2}\right)^{n} x_{n}-x_{n}\right\|=0 .
$$

Then

$$
\begin{aligned}
\left\|\left(P T_{1}\right)^{n} y_{n}-x_{n}\right\| & \leq\left\|\left(P T_{1}\right)^{n} y_{n}-\left(P T_{1}\right)^{n} x_{n}\right\|+\left\|\left(P T_{1}\right)^{n} x_{n}-x_{n}\right\| \\
& \leq k_{n}\left\|y_{n}-x_{n}\right\|+\left\|\left(P T_{1}\right)^{n} x_{n}-x_{n}\right\|
\end{aligned}
$$

gives

$$
\lim _{n \rightarrow \infty}\left\|\left(P T_{1}\right)^{n} y_{n}-x_{n}\right\|=0
$$

From (3.15), and (3.30), we have

$$
\begin{aligned}
\left\|x_{n+1}-x_{n}\right\| & =\left\|\left(1-\alpha_{n}\right)\left(P T_{1}\right)^{n} y_{n}+\alpha_{n}\left(P T_{2}\right)^{n} y_{n}-x_{n}\right\| \\
& \leq\left\|\left(P T_{1}\right)^{n} y_{n}-x_{n}\right\|+\alpha_{n}\left\|\left(P T_{2}\right)^{n} y_{n}-\left(P T_{1}\right)^{n} y_{n}\right\| \\
& \longrightarrow 0 \quad \text { as } n \longrightarrow \infty .
\end{aligned}
$$

Thus from $\left\|x_{n+1}-y_{n}\right\| \leq\left\|x_{n+1}-x_{n}\right\|+\left\|x_{n}-y_{n}\right\|$, we get

$$
\lim _{n \rightarrow \infty}\left\|x_{n+1}-y_{n}\right\|=0
$$

From (3.30), (3.31) and

$$
\left\|x_{n+1}-\left(P T_{1}\right)^{n} y_{n}\right\| \leq\left\|x_{n+1}-x_{n}\right\|+\left\|x_{n}-\left(P T_{1}\right)^{n} y_{n}\right\|,
$$

we have

$$
\lim _{n \rightarrow \infty}\left\|x_{n+1}-\left(P T_{1}\right)^{n} y_{n}\right\|=0 .
$$


Now we make use of the fact that every nonself asymptotically nonexpansive mapping with respect to $P$ must be uniformly $L$-Lipschitzian with respect to $P$ combined with (3.22), (3.32), and (3.34), where $L=\sup _{n \in \mathbb{N}}\left\{k_{n}\right\} \geq 1$, to reach at

$$
\begin{aligned}
\left\|x_{n}-\left(P T_{1}\right) x_{n}\right\| & \leq\left\|x_{n}-\left(P T_{1}\right)^{n} x_{n}\right\|+\left\|\left(P T_{1}\right)^{n} x_{n}-\left(P T_{1}\right)^{n} y_{n-1}\right\|+\left\|\left(P T_{1}\right)^{n} y_{n-1}-\left(P T_{1}\right) x_{n}\right\| \\
& \leq\left\|x_{n}-\left(P T_{1}\right)^{n} x_{n}\right\|+k_{n}\left\|x_{n}-y_{n-1}\right\|+L\left\|\left(P T_{1}\right)^{n-1} y_{n-1}-x_{n}\right\|
\end{aligned}
$$

Thus

$$
\lim _{n \rightarrow \infty}\left\|x_{n}-\left(P T_{1}\right) x_{n}\right\|=0
$$

From (3.24), (3.26), and (3.31), we have

$$
\begin{aligned}
\left\|x_{n+1}-\left(P T_{2}\right)^{n} x_{n}\right\| & \leq\left\|x_{n+1}-x_{n}\right\|+\left\|x_{n}-\left(P T_{2}\right)^{n} y_{n}\right\|+\left\|\left(P T_{2}\right)^{n} y_{n}-\left(P T_{2}\right)^{n} x_{n}\right\| \\
& \leq\left\|x_{n+1}-x_{n}\right\|+\left\|x_{n}-\left(P T_{2}\right)^{n} y_{n}\right\|+k_{n}\left\|y_{n}-x_{n}\right\| \\
& \longrightarrow 0 \text { as } n \rightarrow \infty
\end{aligned}
$$

and so

$$
\lim _{n \rightarrow \infty}\left\|x_{n+1}-\left(P T_{2}\right)^{n} x_{n}\right\|=0
$$

Again making use of the fact that every nonself asymptotically nonexpansive mapping with respect to $P$ must be uniformly $L$-Lipschitzian with respect to $P$ and (3.28), (3.31) and (3.38), we have

$$
\begin{aligned}
\left\|x_{n+1}-\left(P T_{2}\right) x_{n+1}\right\| \leq & \left\|x_{n+1}-\left(P T_{2}\right)^{n+1} x_{n+1}\right\|+\left\|\left(P T_{2}\right)^{n+1} x_{n+1}-\left(P T_{2}\right)^{n+1} x_{n}\right\| \\
& +\left\|\left(P T_{2}\right)^{n+1} x_{n}-\left(P T_{2}\right) x_{n+1}\right\| \\
\leq & \left\|x_{n+1}-\left(P T_{2}\right)^{n+1} x_{n+1}\right\|+k_{n+1}\left\|x_{n+1}-x_{n}\right\|+L\left\|\left(P T_{2}\right)^{n} x_{n}-x_{n+1}\right\| .
\end{aligned}
$$

This gives,

$$
\lim _{n \rightarrow \infty}\left\|x_{n}-\left(P T_{2}\right) x_{n}\right\|=0
$$

This completes the proof of the lemma.

Theorem 3.5. Let $K$ be a nonempty closed convex subset of a real uniformly convex and smooth Banach space $E$ with $P$ as a sunny nonexpansive retraction. Let $T_{1}, T_{2}: K \rightarrow E$ be two weakly inward and nonself asymptotically nonexpansive mappings with respect to $P$ with sequence $\left\{k_{n}\right\} \subset[1, \infty)$ 
satisfying $\sum_{n=1}^{\infty}\left(k_{n}-1\right)<\infty$. Suppose that $\left\{x_{n}\right\}$ is defined by (1.9), where $\left\{\alpha_{n}\right\}$ and $\left\{\beta_{n}\right\}$ are two sequences in $[a, 1-a]$ for some $a \in(0,1)$. If one of $T_{1}$ and $T_{2}$ is completely continuous and $F \neq \emptyset$, then $\left\{x_{n}\right\}$ converges strongly to a common fixed point of $T_{1}$ and $T_{2}$.

Proof. By Lemma 3.1(i), $\lim _{n \rightarrow \infty}\left\|x_{n}-p\right\|$ exists for any $p \in F$. It is sufficient to show that $\left\{x_{n}\right\}$ has a subsequence which converges strongly to a common fixed point of $T_{1}$ and $T_{2}$. By Lemma 3.4, $\lim _{n \rightarrow \infty}\left\|x_{n}-\left(P T_{1}\right) x_{n}\right\|=\lim _{n \rightarrow \infty}\left\|x_{n}-\left(P T_{2}\right) x_{n}\right\|=0$. Suppose that $T_{1}$ is completely continuous. Noting that $P$ is nonexpansive, we conclude that there exists subsequence $\left\{P T_{1} x_{n_{j}}\right\}$ of $\left\{P T_{1} x_{n}\right\}$ such that $P T_{1} x_{n_{j}} \rightarrow p$. Thus $\left\|x_{n_{j}}-p\right\| \leq\left\|x_{n_{j}}-P T_{1} x_{n_{j}}\right\|+\left\|P T_{1} x_{n_{j}}-p\right\|$ implies $x_{n_{j}} \rightarrow p$ as $j \rightarrow \infty$. Again $\lim _{j \rightarrow \infty}\left\|x_{n_{j}}-\left(P T_{1}\right) x_{n_{j}}\right\|=0$ yields by continuity of $P$ and $T_{1}$ that $p=P T_{1} p$. Similarly $p=P T_{2} p$. By Lemma 2.3, $p=T_{1} p=T_{2} p$. Since $F$ is closed, so $p \in F$. Thus $\left\{x_{n}\right\}$ converges strongly to a common fixed point $p$ of $T_{1}$ and $T_{2}$. This completes the proof.

Theorem 3.6. Let $K$ be a nonempty closed convex subset of a real uniformly convex and smooth Banach space $E$ with $P$ as a sunny nonexpansive retraction. Let $T_{1}, T_{2}: K \rightarrow E$ be two weakly inward and nonself asymptotically nonexpansive mappings with respect to $P$ with sequence $\left\{k_{n}\right\} \subset[1, \infty)$ satisfying $\sum_{n=1}^{\infty}\left(k_{n}-1\right)<\infty$. Suppose that $\left\{x_{n}\right\}$ is defined by (1.9), where $\left\{\alpha_{n}\right\}$ and $\left\{\beta_{n}\right\}$ are two sequences in $[a, 1-a]$ for some $a \in(0,1)$. If $T_{1}$ and $T_{2}$ satisfy condition $\left(A^{\prime}\right)$ and $F \neq \emptyset$, then $\left\{x_{n}\right\}$ converges strongly to a common fixed point of $T_{1}$ and $T_{2}$.

Proof. By Lemma 3.1(i), $\lim _{n \rightarrow \infty}\left\|x_{n}-p\right\|$ exists, and so, $\lim _{n \rightarrow \infty} d\left(x_{n}, F\right)$ exists for all $p \in F$. Also, by Lemma $3.4 \lim _{n \rightarrow \infty}\left\|x_{n}-\left(P T_{1}\right) x_{n}\right\|=\lim _{n \rightarrow \infty}\left\|x_{n}-\left(P T_{2}\right) x_{n}\right\|=0$. It follows from condition $\left(A^{\prime}\right)$ and Lemma 2.3 that

$$
\lim _{n \rightarrow \infty} f\left(d\left(x_{n}, F\right)\right) \leq \lim _{n \rightarrow \infty}\left(\frac{1}{2}\left(\left\|x_{n}-\left(P T_{1}\right) x_{n}\right\|+\left\|x_{n}-\left(P T_{2}\right) x_{n}\right\|\right)\right)=0 .
$$

That is,

$$
\lim _{n \rightarrow \infty} f\left(d\left(x_{n}, F\right)\right)=0
$$

Since $f:[0, \infty) \rightarrow[0, \infty)$ is a nondecreasing function satisfying $f(0)=0, f(t)>0$ for all $t \in(0, \infty)$, therefore we have

$$
\lim _{n \rightarrow \infty} d\left(x_{n}, F\right)=0
$$

From Theorem 3.2, we obtain that $\left\{x_{n}\right\}$ is a Cauchy sequence in $K$. Since $K$ is a closed subset of a complete space, there exists a $q \in K$ such that $x_{n} \rightarrow q$ as $n \rightarrow \infty$. Then, $\lim _{n \rightarrow \infty} d\left(x_{n}, F\right)=$ 0 yields that $d(q, F)=0$. Further, it follows from the closedness of $F$ that $q \in F$. This completes the proof.

Theorem 3.7. Let $K$ be a nonempty closed convex subset of a real uniformly convex and smooth Banach space E satisfying Opial's condition with $P$ as a sunny nonexpansive retraction. Let $T_{1}, T_{2}$ : $K \rightarrow E$ be two weakly inward and nonself asymptotically nonexpansive mappings with respect to $P$ with sequence $\left\{k_{n}\right\} \subset[1, \infty)$ satisfying $\sum_{n=1}^{\infty}\left(k_{n}-1\right)<\infty$. Suppose that $\left\{x_{n}\right\}$ is defined by (1.9), 
where $\left\{\alpha_{n}\right\}$ and $\left\{\beta_{n}\right\}$ are two sequences in $[a, 1-a]$ for some $a \in(0,1)$. If $F \neq \emptyset$, then $\left\{x_{n}\right\}$ converges weakly to a common fixed point of $T_{1}$ and $T_{2}$.

Proof. Let $p \in F$. By Lemma 3.1(i), $\lim _{n \rightarrow \infty}\left\|x_{n}-p\right\|$ exists, and $\left\{x_{n}\right\}$ is bounded. Note that $P T_{1}$ and $P T_{2}$ are self-mappings from $K$ into itself. We now prove that $\left\{x_{n}\right\}$ has a unique weak subsequential limit in $F$. Suppose that subsequences $\left\{x_{n_{k}}\right\}$ and $\left\{x_{n_{j}}\right\}$ of $\left\{x_{n}\right\}$ converge weakly to $p_{1}$ and $p_{2}$, respectively. By Lemma 3.4, we have $\lim _{n \rightarrow \infty}\left\|x_{n_{k}}-\left(P T_{i}\right) x_{n_{k}}\right\|=0,(i=1,2)$. Lemma 2.4 guarantees that $\left(I-P T_{1}\right) p_{1}=0$, that is, $\left(P T_{1}\right) p_{1}=p_{1}$. Similarly, $\left(P T_{2}\right) p_{1}=p_{1}$. Again in the same way, we can prove that $p_{2} \in F$. Lemma 2.3 now assures that $p_{1}, p_{2} \in F$. For uniqueness, assume that $p_{1} \neq p_{2}$, then by Opial's condition, we have

$$
\begin{aligned}
\lim _{n \rightarrow \infty}\left\|x_{n}-p_{1}\right\| & =\lim _{k \rightarrow \infty}\left\|x_{n_{k}}-p_{1}\right\| \\
& <\lim _{k \rightarrow \infty}\left\|x_{n_{k}}-p_{2}\right\| \\
& =\lim _{j \rightarrow \infty}\left\|x_{n_{j}}-p_{2}\right\| \\
& <\lim _{j \rightarrow \infty}\left\|x_{n_{j}}-p_{1}\right\| \\
& =\lim _{n \rightarrow \infty}\left\|x_{n}-p_{1}\right\|,
\end{aligned}
$$

which is a contradiction and hence $p_{1}=p_{2}$. As a result, $\left\{x_{n}\right\}$ converges weakly to a common fixed point of $T_{1}$ and $T_{2}$. follows.

In a way similar to the above, we can also prove the results involving error terms as

Theorem 3.8. Let $K$ be a nonempty closed convex subset of a real uniformly convex and smooth Banach space $E$ with $P$ as a sunny nonexpansive retraction. Let $T_{1}, T_{2}: K \rightarrow E$ be two weakly inward and nonself asymptotically nonexpansive mappings with respect to $P$ with sequence $\left\{k_{n}\right\} \subset[1, \infty)$ satisfying $\sum_{n=1}^{\infty}\left(k_{n}-1\right)<\infty$. Suppose that $\left\{x_{n}\right\}$ is the sequence defined by (1.10) satisfying the following conditions:

(i) $\sum_{n=1}^{\infty} \gamma_{n}<\infty, \sum_{n=1}^{\infty} \gamma_{n}^{\prime}<\infty$;

(ii) $\left\{\alpha_{n}\right\}$ and $\left\{\alpha_{n}^{\prime}\right\}$ are two sequences in $[a, 1-a]$ for some $a \in(0,1)$.

If one of $T_{1}$ and $T_{2}$ is completely continuous and $F \neq \emptyset$, then $\left\{x_{n}\right\}$ converges strongly to a common fixed point of $T_{1}$ and $T_{2}$.

Theorem 3.9. Let $K$ be a nonempty closed convex subset of a real uniformly convex and smooth Banach space $E$ with $P$ as a sunny nonexpansive retraction. Let $T_{1}, T_{2}: K \rightarrow E$ be two weakly inward and nonself asymptotically nonexpansive mappings with respect to $P$ with sequence $\left\{k_{n}\right\} \subset[1, \infty)$ satisfying $\sum_{n=1}^{\infty}\left(k_{n}-1\right)<\infty$. Suppose that $\left\{x_{n}\right\}$ is the sequence defined by (1.10) satisfying the following conditions:

(i) $\sum_{n=1}^{\infty} \gamma_{n}<\infty, \sum_{n=1}^{\infty} \gamma_{n}^{\prime}<\infty$;

(ii) $\left\{\alpha_{n}\right\}$ and $\left\{\alpha_{n}^{\prime}\right\}$ are two sequences in $[a, 1-a]$ for some $a \in(0,1)$. 
If $T_{1}$ and $T_{2}$ satisfy condition $\left(A^{\prime}\right)$ and $F \neq \emptyset$, then $\left\{x_{n}\right\}$ converges strongly to a common fixed point of $T_{1}$ and $T_{2}$.

Theorem 3.10. Let $K$ be a nonempty closed convex subset of a real uniformly convex and smooth Banach space E satisfying Opial's condition with $P$ as a sunny nonexpansive retraction. Let $T_{1}, T_{2}$ : $K \rightarrow E$ be two weakly inward and nonself asymptotically nonexpansive mappings with respect to $P$ with sequence $\left\{k_{n}\right\} \subset[1, \infty)$ satisfying $\sum_{n=1}^{\infty}\left(k_{n}-1\right)<\infty$. Suppose that $\left\{x_{n}\right\}$ is the sequence defined by (1.10) satisfying the following conditions:

(i) $\sum_{n=1}^{\infty} \gamma_{n}<\infty, \sum_{n=1}^{\infty} \gamma_{n}^{\prime}<\infty$;

(ii) $\left\{\alpha_{n}\right\}$ and $\left\{\alpha_{n}^{\prime}\right\}$ are two sequences in $[a, 1-a]$ for some $a \in(0,1)$.

If $F \neq \emptyset$, then $\left\{x_{n}\right\}$ converges weakly to a common fixed point of $T_{1}$ and $T_{2}$.

\section{Acknowledgments}

The authors are extremely grateful to the referees for useful suggestions that improved the content of the paper. This paper was supported by Ataturk University Rectorship under "The Scientific and Research Project of Ataturk University," Project no: 2010/276.

\section{References}

[1] C. E. Chidume, E. U. Ofoedu, and H. Zegeye, "Strong and weak convergence theorems for asymptotically nonexpansive mappings," Journal of Mathematical Analysis and Applications, vol. 280, no. 2, pp. 364-374, 2003.

[2] R. P. Agarwal, D. O'Regan, and D. R. Sahu, "Iterative construction of fixed points of nearly asymptotically nonexpansive mappings," Journal of Nonlinear and Convex Analysis, vol. 8, no. 1, pp. 61-79, 2007.

[3] G. Das and J. P. Debata, "Fixed points of quasinonexpansive mappings," Indian Journal of Pure and Applied Mathematics, vol. 17, no. 11, pp. 1263-1269, 1986.

[4] W. Takahashi and T. Tamura, "Limit theorems of operators by convex combinations of nonexpansive retractions in Banach spaces," Journal of Approximation Theory, vol. 91, no. 3, pp. 386-397, 1997.

[5] S. H. Khan and W. Takahashi, "Approximating common fixed points of two asymptotically nonexpansive mappings," Scientiae Mathematicae Japonicae, vol. 53, no. 1, pp. 143-148, 2001.

[6] W. Takahashi, "Iterative methods for approximation of fixed points and their applications," Journal of the Operations Research Society of Japan, vol. 43, no. 1, pp. 87-108, 2000.

[7] K. Goebel and W. A. Kirk, "A fixed point theorem for asymptotically nonexpansive mappings," Proceedings of the American Mathematical Society, vol. 35, pp. 171-174, 1972.

[8] S. H. Khan and N. Hussain, "Convergence theorems for nonself asymptotically nonexpansive mappings," Computers \& Mathematics with Applications, vol. 55, no. 11, pp. 2544-2553, 2008.

[9] H. K. Pathak, Y. J. Cho, and S. M. Kang, "Strong and weak convergence theorems for nonselfasymptotically perturbed nonexpansive mappings," Nonlinear Analysis: Theory, Methods E Applications, vol. 70, no. 5, pp. 1929-1938, 2009.

[10] L. Wang, "Strong and weak convergence theorems for common fixed point of nonself asymptotically nonexpansive mappings," Journal of Mathematical Analysis and Applications, vol. 323, no. 1, pp. 550-557, 2006.

[11] L. Yang, "Modified multistep iterative process for some common fixed point of a finite family of nonself asymptotically nonexpansive mappings," Mathematical and Computer Modelling, vol. 45, no. 9-10, pp. 1157-1169, 2007.

[12] S. Thianwan, "Common fixed points of new iterations for two asymptotically nonexpansive nonselfmappings in a Banach space," Journal of Computational and Applied Mathematics, vol. 224, no. 2, pp. 688-695, 2009. 
[13] H. Y. Zhou, Y. J. Cho, and S. M. Kang, "A new iterative algorithm for approximating common fixed points for asymptotically nonexpansive mappings," Fixed Point Theory and Applications, vol. 2007, Article ID 64874, 10 pages, 2007.

[14] H. F. Senter and W. G. Dotson, Jr., "Approximating fixed points of nonexpansive mappings," Proceedings of the American Mathematical Society, vol. 44, pp. 375-380, 1974.

[15] S. H. Khan and H. Fukhar-ud-din, "Weak and strong convergence of a scheme with errors for two nonexpansive mappings," Nonlinear Analysis: Theory, Methods \& Applications, vol. 61, no. 8, pp. 12951301, 2005.

[16] H. Zhou, R. P. Agarwal, Y. J. Cho, and Y. S. Kim, "Nonexpansive mappings and iterative methods in uniformly convex Banach spaces," Georgian Mathematical Journal, vol. 9, no. 3, pp. 591-600, 2002.

[17] J. Schu, "Weak and strong convergence to fixed points of asymptotically nonexpansive mappings," Bulletin of the Australian Mathematical Society, vol. 43, no. 1, pp. 153-159, 1991.

[18] W. Takahashi, Nonlinear Functional Analysis: Fixed Point Theory and Its Applications, Yokohama Publishers, Yokohama, Japan, 2000. 


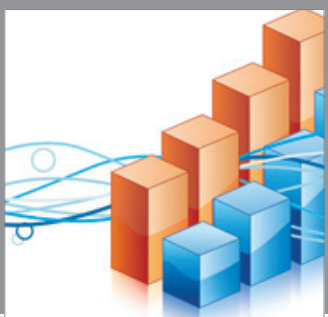

Advances in

Operations Research

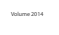

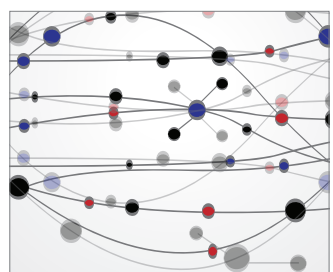

\section{The Scientific} World Journal
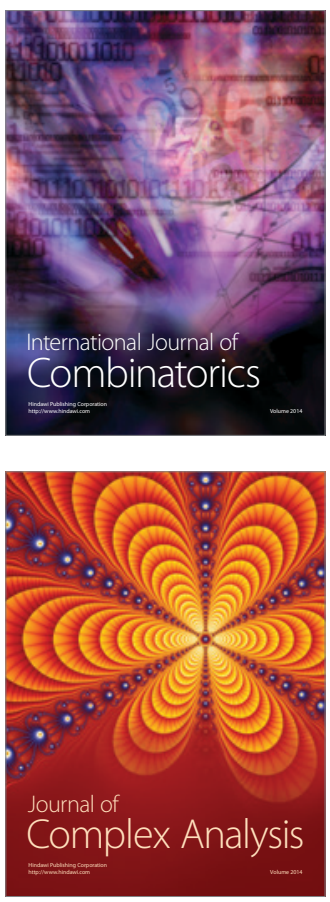

International Journal of

Mathematics and

Mathematical

Sciences
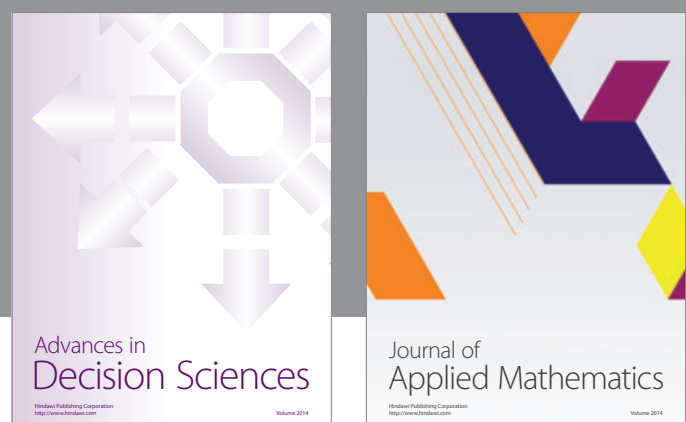

Journal of

Applied Mathematics
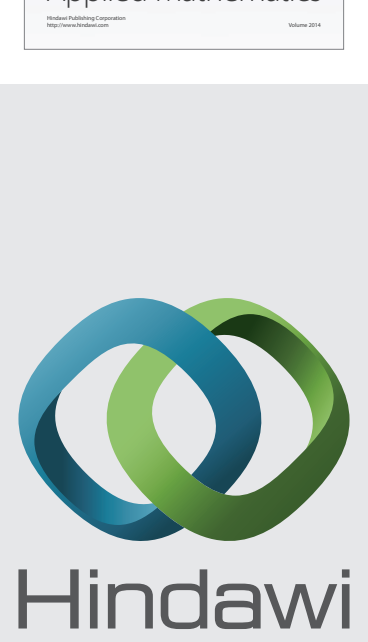

Submit your manuscripts at http://www.hindawi.com
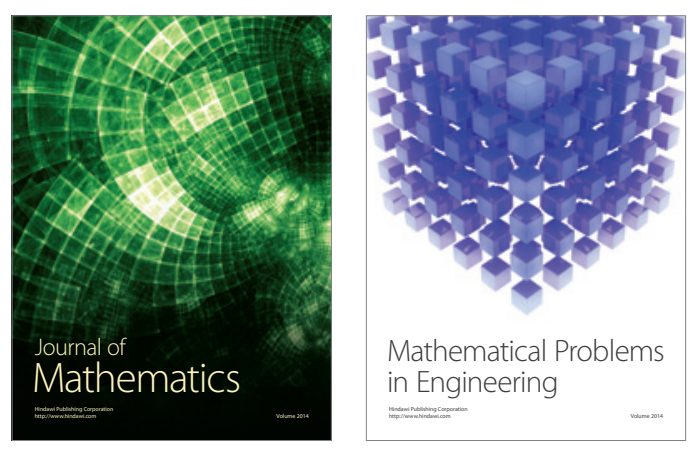

Mathematical Problems in Engineering
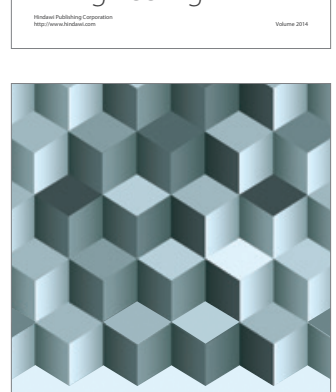

Journal of

Function Spaces
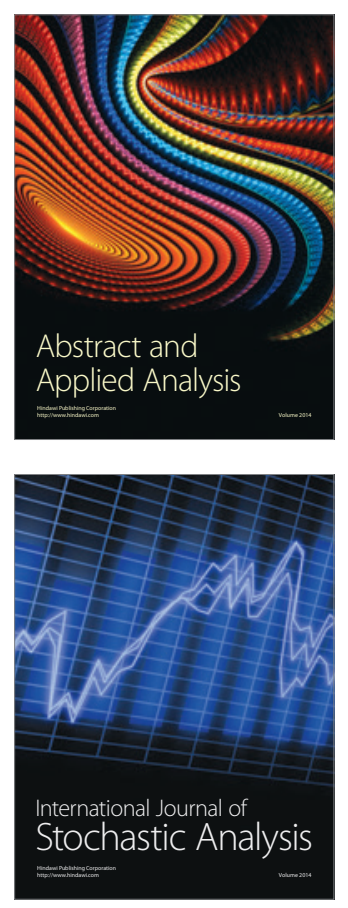

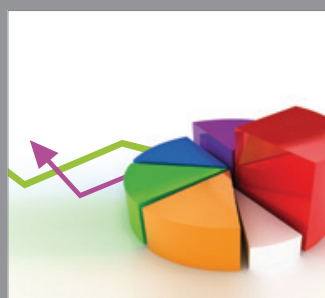

ournal of

Probability and Statistics

Promensencen
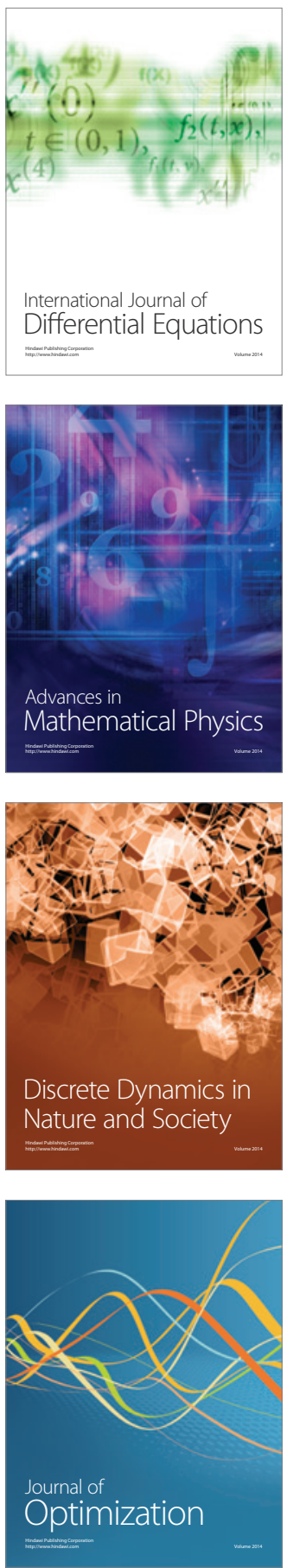